\title{
Intersecting Missions, Converging Practice
}

I AM ESPECIALLY PLEASED to have been asked to contribute to this issue of RBM, focusing as it does on the convergence of libraries, museums, and archives. This has been a major interest of mine for a long time, and almost all of my professional experience has been within institutions housing collections comprising not only rare books and other library materials, but also incorporating rich assemblages of institutional archives, historical and literary manuscripts, maps, prints, photographs, oral history resources, works of art, and artifacts.

As Director of the Institute of Museum and Library Services (IMLS), I found myself in a position to identify the points of intersection between the library and museum communities and was specifically responsible by statute for fostering collaboration between and among these institutions. And while not explicitly mentioned in the agency's name, archives are very definitely part of the mix supported by IMLS. My own perspective on the relationship among cultural heritage agencies_including libraries, museums, and archives - is thus informed by my long experience working in institutions that occupied a place on the boundaries of library, archives, and museum professional practice. And as Paul Tillich once observed, "the boundary is the best place for acquiring knowledge." Allow me therefore to make some observations from the perspectives of the boundaries and, from there, I hope, to contribute something to the understanding of our work.

\section{Are We Converging?}

"Are we converging?" Perhaps an unstated question is: "Is that a good thing?" I believe we all can acknowledge that in some very important ways our missions do indeed intersect. In his article, Bruce Whiteman has noted the Venn diagram-like notion of overlapping aspects of our activities and practices. Indeed, throughout this issue of $R B M$ there are references to some unmistakable and undeniable indicators that our futures are indeed intertwined, if not converging. Let us take a look at some of these.

1. Paul Tillich, On the Boundary (New York: Chas. Scribners, 1966), p. 13. 
First, we must recognize that all libraries, archives, and museums share a common institutional ancestry. The earliest libraries known to history were in actuality archives. What historians often refer to as "temple libraries" or "palace libraries" were collections of texts (cuneiform tablets) that documented the official religious activities of the temple or the government transactions of the palace court. Later, collections of other kinds of texts were called "museums," in that they were buildings dedicated to honoring the muses. The great library of Alexandria, for example, was in fact called the Museon, a temple to the muses.

In practice, there was little practical differentiation between a library and a museum until the early modern period, when the development of typographic printing resulted in a dramatic increase in the volume of texts available, which were then distinguished from a collection of objects, library from museum. The practice of separating official records from other kinds of documents also arose around the same time, developing from the rational bureaucratization of governments.

For at least the last century or more, librarians, archivists, and museum professionals (if not always the general public) have typically viewed the agencies and collections that they manage as distinct. While all three of these types of cultural heritage agencies have carefully constructed collections of rich resources, organized them and made them available to various publics, and preserved them for transmission from one generation to the next, we have always drawn careful distinctions between them, usually based on the nature of their respective collections. We all seem to be confident that libraries, archives, and museums collect different types of things-libraries collect documents of various kinds (books, journals, maps, and the like), archives collect documents of a specific kind (records containing particular types of evidence), and museums collect objects and artifacts.

There is a robust conceptual framework going back almost a century, however, that provides a foundation for a different analysis, one that would indicate that the distinctions we commonly make between our kinds of collections are irrelevant. I have spoken on many occasions about the blurring of such boundaries. The conclusions of this argument are simply that all of the things that we collect-books, journals, prints, photographs, manuscripts, paintings, objets d'art of all kinds, all scientific specimens, anything at all that you might find in any museum collection —everything we collect is really a "document." According to David Levy’s simple definition, all documents are "quite simply, talking things. They are bits of the material world—clay, stone, animal skin, plant fiber, sand—-that we've imbued with the ability to speak."

2. David M. Levy, Scrolling Forward: Making Sense of Documents in the Digital Age (New York: Arcade, 2001), p. 23. 
If one accepts this stance, then the distinctions we have drawn between libraries, museums, and archives, based on the kinds of things they collect, are really a matter of convention - conventions that have evolved over time. The boundaries between types of cultural heritage institutions that we now accept as common are simply lines that we ourselves have drawn. And we can re-draw them ourselves if we choose to do so. I believe that nowadays the general public sees little significant difference between libraries, archives, and museums. This perception is driven in part by the experience of people who use our resources in the digital environment.

In recent years, we have collectively created a substantial amount of cultural content in digital form. The accessibility of collections of digital surrogates through the Web has led to transformations in the use of materials from library, archival, and museum collections. People who formerly utilized such materials on site in our respective institutions are now frequently (if not exclusively) consulting them online. Even more significantly, large numbers of individuals who previously made little or no use of these materials - who were perhaps even unaware of their existence-are now frequently accessing these digital collections. It is extremely important to realize that these new users do not care whether the original materials are in a library or a museum or an archives, and may not even be aware that they exist. They just want access to "the stuff." They find it on the Web, they download it to their desktop, and they repurpose it in ways we could never have anticipated.

The real challenge emerges when users go in search of the actual or authentic document (and the remarkable thing is that they quite often do), and they manage to locate the original in one of our collections. These new users are often mystified and feel defeated if they find that these resources are scattered across a wide range of agencies and institutions, each of which has its own peculiar rules and procedures, each with cultures and systems that may differ dramatically—all of which inhibits access. When they discover that the resources they found so accessible and easily manipulated in the digital context are so diffuse and difficult to approach in the real world, they often become frustrated. They may not understand-and come to question the value of-our differing professional identities and cultures.

Another indicator of a convergence has been mentioned in passing by several authors in this issue. Over the past decade or so, we have witnessed a remarkable evolution of formal governmental structures for funding and managing cultural heritage resources. In the United Kingdom, we have seen the reorganization of existing bureaucracies into the Museum, Library and Archives Council, a new construction that provides funding and overall direction for all three sectors. In the United States, the creation in 1996 of the Institute of Museum and Library Services, formed by merging the Office of Library Programs in the Department of 
Education with the Institute of Museum Services, has had a profound effect on the funding of these programs and the nature of the projects it supports. The statute establishing the IMLS mandates that its funds be used to foster collaboration between and among museums and libraries, and this carrot has led to some very interesting developments in the U.S. cultural heritage scene.

Michelle Doucet has also described the remarkable transformation in Canada that resulted from the merger of the National Library and the National Archives to form a single structure, Library and Archives Canada. There have been similar developments in Norway and in Finland. Gerald Beasley suggested that some of this restructuring may be nothing more than a renaming or rebranding of existing organizations and institutions. If so, then perhaps it is in the context of the Confucian concept of the "Rectification of Names." When asked what he would do first were he to take over the administration of the kingdom, Confucius replied: "The one thing needed is the rectification of names." China's greatest sage explained that if names were incorrect, words would be misused, and when words were misused, nothing could be on a sound footing. Law and punishments would not be just, and people would not know where to place hand or foot.

Perhaps these new bureaucratic alignments are merely an indication of a rectification of names. But whether these structures are simply the result of governmental tinkering to reduce staff and encourage efficiency through reorganization, or whether they result from the recognition of a fundamental convergence of mission, only time will tell.

\section{Real Differences}

In spite of their similarities, and in spite of the apparent momentum toward convergence, libraries are not archives and museums are not libraries. There are very real differences between these cultural heritage agencies. The most obvious differences are governance and funding. Most libraries (and archives) are units of governments and are funded for the most part with the same direct appropriations that fund their parent organizations. To be sure, they must compete for resources in often Darwinian budget struggles. Nevertheless, their funding comes primarily from above.

Most museums, in contrast, are independent and private not-for-profit organizations. They depend on a wide range of sources for funding, including government appropriations, corporate grants and contracts, benefactions of individuals and foundations, and substantial streams of self-generated revenue. Such differences have a profound effect on the way these institutions operate and on the outlook of their leadership, and dramatically affect their governance structures, often elevating the critical role of the board of directors and executive leadership. 
Another important distinction is the way our collections are used. It has been recognized that there is a fundamental difference between "viewing" a collection, as is typical in a museum setting, and "using" or "reading" library and archival materials. Gerald Beasley asserted that "books fail as museum objects." If true, this is almost certainly because books-most books anyway-were never meant to be viewed through the glass of an exhibition case. They were intended to be held in the hand or laid upon the lectern and read, a process that is intense and individualized, in which the author's ideas are perceived through the lens of the reader's own experience and perceptions, or what Beasley called "empathetic access."

That said, however, it is important for us to focus for a moment on the fact that not all museums are alike. Indeed, before I went to IMLS, I thought that there was great diversity among libraries in terms of their collections, their institutional framework, and the publics that they serve. At IMLS, however, I learned that, in comparison to museums, libraries are basically alike. The differences among museums are extraordinary.

For most of us who come from library and archival backgrounds, the word "museum" conjures up an image such as the Metropolitan Museum of Art: a grand building with a spectacular collection of art objects that mounts blockbuster exhibitions. In point of fact, such museums are the exception rather than the norm. The museum world encompasses a vast array of very different institutions that support a variety of learning activities, including everything from aquaria to zoos. Local history museums, which are often poorly funded and staffed by untrained local history volunteers, comprise the largest segment of the museum community. The fastest growing segment of the museum world is the children's museum, which typically has no collections and mounts no exhibitions. My point is simply that we must not base assessments of overlapping missions and potential convergence on misleading stereotyped notions of what museums are and what they do. Some museums are much more like libraries than they are like other museums. I would assert, for example, that natural science museums, with their taxonomic collections, have more in common with research libraries, in both their processes and their use, than they have with art museums.

Another—and perhaps more fundamental—difference between museums, libraries, and archives is in the nature and preparation of the personnel who work in them. Almost all librarians, including those who work in special collections, have earned a master's degree from a program accredited by the American Library Association. The ALA accreditation standards ensure a certain amount of homogeneity across these programs. This shared background, we like to think, provides a common 
ground of values and ethics, and mutually held perspectives on building collections and providing services.

Interestingly, the vast majority of archivists entering into practice today have also earned a master's degree from a school of library and information studies program that features a strong archival specialization. This transformation in archival education is striking. Why has it happened? There are a number of reasons, but allow me to focus attention on one specific contributory cause.

Perhaps the single most important factor in shifting the locale of professional education for archivists was the emergence of the MARC AMC (MAchine-Readable Cataloging for Archival and Manuscripts Control) format as the standard for collection (or record group) level description. Over the years, archivists came to recognize the need for standards of archival description and very wisely decided that, rather than develop their own standards, it was better to adapt an existing one, namely MARC. RLG's implementation of that standard resulted in a sudden emergence of archival resources into library bibliographic systems. In turn, this movement fostered the need for archivists to have some background and expertise in managing those systems. In short, archivists decided to use a librarian's tool to manage one of the most important aspects of their work. The line between archivist and librarian suddenly became much less distinct.

By contrast, museum professionals do not share this common type of professional preparation. They come to their work from greatly varying educational backgrounds and fields of experience and are art historians, scientists, or educators by training. Consequently, they often do not have a strongly developed sense of a profession with shared values and ethics, but rather tend to derive their identity as much from their academic discipline as from their professional practice.

\section{Common Themes}

One important theme is the imperative to collaborate. This is a theme that I find quite congenial, because at IMLS we were under statutory mandate to encourage collaboration. The kind of collaboration we have tried to foster at IMLS is neither a joined-at-the-hip symbiosis nor a parasitic relationship. Rather, it is a mature and reflective recognition of intersecting nodes of interest, activity, and mission that offers the opportunity for creating synergy out of cooperation, building a structure in which the whole is greater than the sum of the parts.

Collaboration, however, is not easy. It requires that we, as individuals and as institutions, behave in ways that are not "normal," that feel unnatural. One definition of collaboration is "an unnatural act, practiced by non-consenting adults." The 
American Heritage College Dictionary, in fact, offers the following as one definition: "cooperating treasonably, as with an enemy occupying one's country." This notion may be at the heart of some of the difficulties that we encounter in attempting to collaborate. I submit that a better definition for our purposes is "working together in a joint effort."

Differences among institutions, however, can be profound. The assets and personnel, academic preparation of professionals - even the very vocabulary we use to describe our operations - can be dramatically different. The characteristics and proximity to the communities served can vary widely. Values and assumptions of mission and service can be different. In short, differences in organizational culture are real, they are challenging, and they do not go away. It is imperative that these differences be recognized and addressed forthrightly. Over time, I believe they can evolve into sources of synergy rather than contention. One goal of successful collaboration is the assurance that the integrity of each institution is sustained by the partnership.

Another theme is the need to focus on our users. The difficulty is that libraries, museums, and archives do not think about users in the same way. In fact, we cannot even agree on how to talk about them. We call our users by a wide variety of names: audiences, visitors, readers, researchers, patrons, clients, customers. These greatly varying names imply to me greatly varying notions of the relationship between institutions and their publics. I invite you to consider, for example, the difference in connotation between the term "patron" as used in a library and in a museum.

The fact of the matter is that we have only a vague idea of who our users are and why they access our collections. Our experience with visitors to our digital collections seems to indicate that there would be many more potential users out there if we could only reach them and make them aware of our resources and programs. There is much work to do in this area. Yet I am convinced that there is a great deal of overlap among our audiences, and we might better serve them by making our practices and policies more uniform. Part of the difficulty, it seems to me, is that we expect our users to experience us on our terms, rather than adjusting ourselves

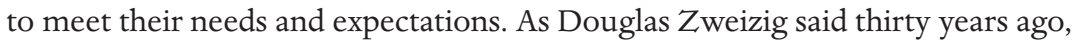
"Librarians have for too long thought of the user in the life of the library; we need instead to think of the library in the life of the user."

This leads me to another recurring theme: creating and demonstrating value. My thinking about libraries, archives, museums, and other public cultural agencies has been influenced by Mark Moore's book Creating Public Value: Strategic Management

3. Douglas L. Zweizig, Predicting Amount of Library Use: An Empirical Study of the Role of the Public Library in the Life of the Adult Public (Ph.D. dissertation, Syracuse University, 1973), p. 15. 
in Government. ${ }^{4}$ Moore asserts that just as the aim of the manager in the private sector is to produce private value in the form of revenue, profit, and capital growth, so, too, the aim of managerial work in the public sector is to produce public value. In one sense, this is perfectly obvious: if public enterprises do not create value for the public, then why should they be formed or continue to exist? The problem, of course, is how to define and measure public value.

There is really nothing new about this notion. John Cotton Dana was director of both the city library and the city museum in Newark, New Jersey. In 1920, Dana wrote:

All public institutions ... should give returns for their cost; and those returns should be in good degree positive, definite, visible, measurable. The goodness of a museum is not in direct ratio to the cost of its building and the upkeep thereof, or to the rarity, auction value, or money cost of its collections. A museum is good only insofar as it is of use ... Common sense demands that a publicly supported institution do something for its supporters and that some part at least of what it does be capable of clear description and downright valuation. ${ }^{5}$

A key concept in determining public value is that it is determined not by the providers of services, but by the consumers of those services. In other words, we do not get to decide what is valuable; our users make that decision. If we want to offer services that the public will value and support, it is imperative that we listen carefully and systematically to that public to understand fully their agendas, concerns, and goals. We also need to develop realistic measures of our success or lack thereof.

\section{Conclusion}

Are our missions intersecting? Are we converging? It seems clear to me that libraries, archives, and museums are all social agencies that are collectively responsible for preserving the shared knowledge of humankind, making it available for everyone to use, and transmitting it to future generations. Our notions about what distinguishes one of us from the other are predicated on outmoded concepts of uniqueness. The impact of digital information technology has lifted the veil that once obscured our common mission. Now that the users of our collections in the digital world fail to recognize the distinctions that we have created, we must find ways to work together more effectively and to share our rich resources among ourselves and enhance public access to them.

4. Mark Moore, Creating Public Value: Strategic Management in Government (Cambridge, Mass.: Harvard University. Press, 1995).

5. John Cotton Dana, The New Museum: Selected Writings by John Cotton Dana. Edited by William A. Penniston (Newark, N.J.: The Newark Museum Association.; Washington, D.C.: American Association of Museums, 1999), pp. 65-66. 
We need to think much more broadly, to envision a seamless learning infrastructure, one that stimulates and supports learning for people of all ages, in all circumstances. If we are truly to empower individuals to fulfillment, to enable them to maximize their human potential, to become contributing members of the knowledge economy, and to participate effectively in civic affairs, then we must build a fabric of social agencies that facilitates continuous lifelong learning. Such a fabric must integrate all of our current social agencies_-including schools, libraries, museums, archives, television, radio, and a host of other organizations and agencies-to create, manage, and provide access to resources for learning.

It seems to me that the biggest impediment to achieving this vision is our own respective notions of professional identity and culture. If we could posit that librarians, archivists, and museum professionals are not separate and distinct professions but, rather, different facets of a single unified profession, I believe that we would find our ability to serve the needs of our communities strengthened. If we reenvision ourselves as public servants, charged with the responsibility for collecting and organizing the materials that document our rich and diverse cultural heritage and enhancing access to those materials for our communities, we will discover that we can reshape our practices, learn from one another, and better meet the needs of our users.

Would such a convergence be a good thing? From the perspective of the professionals who manage cultural heritage agencies, this may be an open question. But from the perspective of the users of our collections - the communities that we seek to serve- how can it be seen as anything other than a strengthening of our cultural heritage infrastructure and an enhancement of our free-choice learning resources? And I ask you: is that not a shared, common raison d'etre of the librarian, the archivist, and the museum professional?

INDEX TO ADVERTISERS 